CIRJE-F-999

\title{
Reputational Effects in Sovereign Default
}

\author{
Konstantin Egorov \\ Pennsylvania State University \\ Michal Fabinger \\ The University of Tokyo
}

January 2016

CIRJE Discussion Papers can be downloaded without charge from:

http://www.cirje.e.u-tokyo.ac.jp/research/03research02dp.html

Discussion Papers are a series of manuscripts in their draft form. They are not intended for circulation or distribution except as indicated by the author. For that reason Discussion Papers may not be reproduced or distributed without the written consent of the author. 


\title{
Reputational Effects in Sovereign Default*
}

\author{
Konstantin Egorov \\ Pennsylvania State University
}

\author{
Michal Fabinger ${ }^{\dagger}$ \\ University of Tokyo
}

First version: March 2015

This version: January 2016

\begin{abstract}
We present a tractable, quantitative model of sovereign borrowing that delivers empirically relevant regularities, such as graduation from default, sovereign debt spreads that may be high for an extended period of time, high debt-to-GDP ratios, and high default rates. The model is an asymmetric-information extension of otherwise standard models of endogenous default on sovereign debt, with borrowing levels determined in equilibrium. Governments could be of different types based on their level of responsibility (cost of default as perceived by the politicians). Only the governments observe their level of responsibility. International investors try to infer the unobserved types based on the history of all observable actions, which gives irresponsible politicians an incentive to choose the same actions as responsible ones would. Governments could tolerate periods of high interest rates without defaulting to signal that they are of better type and to gain good reputation. This leads to lower interest rates during future recessions. For the same reason, even responsible governments should pay at first high interest rates in order to signal their type and thus "graduate from default" afterwards. A calibrated version of the model features these regularities, matches standard business cycle moments, and leads to a more realistic default rate in equilibrium, with parameter values same as in the existing literature.
\end{abstract}

${ }^{*}$ We are grateful to Saroj Bhattarai, Alessandro Dovis, Bulat Gafarov, Gita Gopinath, Barry Ickes, Boyan Jovanovic, Nobuhiro Kiyotaki, Dmitry Mukhin, seminar participants at the Pennsylvania State University, and conference participants at the 2015 Japanese Economic Association Meeting at Keio University for helpful comments and suggestions, and Konstantin Kucheryavyy for his insightful comments as a discussant. We thank Shogo Sakabe, Mengli Sha, Fangyuan Yi, and Wonseok Yoo for excellent research assistance in 2013-2015. Any errors are, of course, our own. This work was supported by the Japan Science and Technology Agency and the Japan Society for the Promotion of Science.

${ }^{\dagger}$ Egorov: 303 Kern Building, Pennsylvania State University, University Park, PA 16802, USA; kze112@psu.edu. Fabinger: Economics Research Building, 7-3-1 Hongo, Bunkyo-ku, University of Tokyo, Tokyo 113-0033, Japan; fabinger@e.u-tokyo.ac.jp. Michal Fabinger is a Research Associate at CERGE-EI, Prague, the Czech Republic. 


\section{Introduction}

In virtually any debt market the reputation of the borrower plays an important role in determining the borrowing terms. Borrowers with better reputation are either charged lower interest rates or face higher debt limits or both. In sovereign debt markets multiple agencies provide credit ratings for individual countries. Changes in credit ratings are often followed by significant changes in sovereign bond spreads, which indicates the importance of reputational effects in sovereign debt markets.

In the model of this paper we focus on the role of one factor that determines the credit ratings: how the history of country's actions affects the extent of information asymmetry regarding the trustworthiness of the government. Specifically, there could be numerous unobserved characteristics of sovereign governments that might affect the default risk. Examples include the severity of economic problems that a potential default would cause, the "responsibility" level of politicians in power and their hidden intentions, as well as misreported GDP figures or the size of the national budget deficit. ${ }^{1}$ While all of these possibilities may be important, for modeling purposes we use the assumption that the information asymmetry concerns only the level of the cost of default, i.e. a proportional output loss that would follow the government's decision not to meet its obligations to the creditors.

Our model features borrowers of several unobserved types characterized by different levels of the cost of default. In this setting any observable action by the borrowers could potentially reveal some information about their type. Thus an "irresponsible" borrower (a borrower with a low cost of default) has an incentive to take the same observable actions as those chosen by a "responsible" borrower (with a high cost of default). We study a Markovian equilibrium in which non-defaulting countries with the same observable characteristics pool together and choose the same observable action, i.e. the same amount of current borrowing. Whether or not the government defaults does reveal information, however. In this sense, the equilibrium is separating with respect to the default decision, but pooling with respect to the consumption choice of non-defaulting countries.

\footnotetext{
${ }^{1} \mathrm{~A}$ recent example comes from the experience of Greece: "In February 2010, the new government of George Papandreou [...] admitted a flawed statistical procedure previously had existed [...] and revised the 2009 deficit from a previously estimated 6\%-8\% to an alarming 12.7\% of GDP. In April 2010, the reported 2009 deficit was further increased to $13.6 \%$, and at the final revised calculation by Eurostat's standardized method had been performed, it ended at $15.7 \%$ of GDP [...]", according to Wikipedia.
} 
Our model exhibits "graduation from default", a phenomenon empirically documented by Reinhart and Rogoff (2009) and Qian, Reinhart, and Rogoff (2010). They find that if a country avoids sovereign debt crises for several decades, the risk of future crises declines substantially. They emphasize that this is a very slow process. Specifically, they state that "crisis recidivism distributions have very fat tails, so that it takes at least 50 and perhaps 100 years to meaningfully speak of "graduation"." In our model the country slowly graduates from default as it gains reputation by not defaulting at times of recessions. After sudden and deep recessions, the country's reputation increases by much more than after gradual and mild recessions. For this reason, the process of graduating from default may take a considerable amount of time, because sudden and deep recessions are infrequent events.

Another feature of our model is that countries can pay high interest rates for prolonged periods of time. With information asymmetry the countries have an incentive to signal a high responsibility level, which requires them to meet their obligations to the creditors when the default risk is perceived to be high. The signaling process could take time, as responsible borrowers may have to wait until the time when irresponsible borrowers would have defaulted. Without information asymmetry there is no incentive to wait to signal one's type, and thus uncertainty associated with high interest rates would be resolved quickly.

Our model delivers a higher default rate than its counterpart with perfect information. Without information asymmetry countries are discouraged from borrowing too much, since as they get closer to defaulting they face very high interest rates. With imperfect information this incentive to behave responsibly is missing, because the creditors do not know how close to defaulting each individual country is. For this reason countries with low cost of default may borrow more than they are willing to repay, which leads to a high default rate.

\section{$1.1 \quad$ Related literature}

In this paper we focus on sovereign debt markets with information asymmetry that is highly persistent. Different aspects of the paper are related to different parts of the literature. We briefly comment on them, and for the reader's convenience highlight similarities to and differences from our model.

One of the first papers that studied information asymmetry in sovereign borrowing was Cole, 
Dow, and English (1995), which featured infinite horizon, but the private information was revealed within one period. The literature that followed often considered models with three periods only in order to make the modeling tractable. This was sufficient to reach interesting qualitative conclusions. Examples include Sandleris (2008, 2014), Catao, Fostel, and Kapur (2009), Catao, Fostel, and Ranciere (2014).

Alfaro and Kanczuk (2005) developed an infinite horizon model that featured persistent information asymmetry. For tractability reasons the model involved two types of government of the borrowing country, three possible values of technology shocks, and a constant debt level. Since the full Bayesian equilibrium would be hard to compute, the authors chose to work with three possible values of the creditors' beliefs about the government: good type with certainty, bad type with certainty, or equal probabilities of either type.

Onder (2014) builds a qualitative infinite-horizon model of graduation from default with two types of government, only one of which can receive signals about the economy's fundamentals. A government may pretend to have received a good signal in order to improve its borrowing terms. The fundamental shocks are i.i.d., and over the long run the creditors can statistically infer the government's type from its past behavior. Barrett (2015) uses a calibrated imperfect-information model of sovereign debt to study post-default spreads; to address this question it turned out not to be necessary to endogenize the country's consumption decisions (primary surpluses).

Similar reputation mechanisms have been considered outside of the sovereign debt literature. In consumer finance, Chatterjee, Corbae and Ríos-Rull (2011) consider credit ratings in unsecured debt markets and provide a quantitative calibration of a three period version of the model. In public policy, Phelan (2006) builds a model where government reputation is gained gradually, with the focus on confiscation of output by the government.

Cole, Neuhann, and Ordonez (2015) studied creditors' endogenous choices to acquire information at a finite cost, in a three period model of sovereign debt. This is distinct from much of the remaining literature, including our paper, where information is costlessly acquired by observing borrower's actions.

Other strands of the literature, such as Dovis (2014) and Phan (2014), explored models with truth-telling equilibria, where different types of government always distinguish themselves by their actions. 
The paper most closely related to ours is D'Erasmo (2011), which features two types of government that differ by their discount rate. Creditors' beliefs are updated based on the government's borrowing and default decisions. When the two types choose the same actions, no private information is revealed, and when they choose different actions, all private information is revealed. This modeling choice is sufficient to obtain a default rate and a debt-to-GDP ratio higher than in perfect information models. Our model allows for a gradual updating of creditors' information instead of receiving all information at once. This brings us closer to the data, where credit ratings do not usually jump from a low value to the highest possible value at any given moment.

\section{Model}

Our model is generalization of Aguiar and Gopinath (2006) and Arellano (2008) to the case of asymmetric information about the cost of default.

Consider a small open economy with a stochastic endowment stream, $y_{t}$. Specifically, we assume that $y_{t}=e^{z_{t}}$, where $z_{t}$ is an $\operatorname{AR}(1)$ process $z_{t}=\rho_{z} z_{t-1}+\varepsilon_{t}$ with persistence $\rho_{z}$ and i.i.d. normal innovations, $\varepsilon_{t} \sim N\left(0, \sigma_{z}\right){ }^{2}$ The objective of the country (government) is to maximize an expected discounted stream of CRRA utility derived from consumption in each period, $u\left(c_{t}\right)=c_{t}^{1-\gamma} /(1-\gamma)$.

The country can borrow from risk-neutral foreign creditor using a one-period bond, which is the only asset in the model. ${ }^{3}$ The country may be in a default state, denoted "B" ("bad state"), or in a non-default state, denoted "G" ("good state"), with transitions between those states as in Arellano (2008). The government can choose to default at any time. During default the country is completely excluded from international financial markets: it can neither save nor borrow. In addition, it suffers from a proportional output loss $x$, i.e., its net income in a default state is $(1-x) y_{t}$. Each period the country may return to the non-default state with an exogenous probability of "redemption" $\lambda$.

The cost of default $x$ is known to the government itself, but is otherwise unobserved. The value of $x$ may change following default, but is constant at other times. After default, the country draws a new random value of $x$ with an exogenous probability distribution function $\varphi(x)$ with support in $\left[x_{\min }, x_{\max }\right]{ }^{4}$

\footnotetext{
${ }^{2}$ Here we normalize the average income to one.

${ }^{3}$ If the country has a positive asset position, this is interpreted as a risk-free bond issued by the rest of the world.

${ }^{4}$ Assuming that $x$ is constant allows us to reduce the number of state variables describing beliefs of creditors. Assuming that $x$ is redrawn after every default prevents the model from converging to the full information model
} 
More broadly, one possible justification for these assumptions could involve the following political economy consideration. There are "responsible" and "irresponsible" politicians in charge, whose type is unobserved by outsiders. When a politician defaults, there is a government change, and a new politician of unknown type comes to power. In the model we describe politicians' type in a stylized, "reduced form" way using the value of cost of default. However, for many features of the model this assumption does not seem to be crucial. For example, as in D'Erasmo (2011) imperfect information about country's discount factor can lead to qualitatively similar results. Thus we interpret imperfect information about $x$ not literally as imperfect information about output drop during default episodes, but rather as all information that influences the default decision and is unobserved by international creditors.

Foreign creditors have rational expectations (beliefs) about the value of $x$, and they update them in a Bayesian fashion. In this environment, country's actions influence the beliefs. We construct an equilibrium that is separating with respect to the default decision, but pooling with respect the choice of level of debt. We assume and verify later that the default decision is monotone in $x$. For this reason, in the non-default state the updated beliefs of creditors at any given time may we written as $1_{x \geq x_{b}} \varphi(x) / \int_{x_{b}}^{x_{\max }} \varphi(x) d x$ for some definite $x_{b}$. Therefore the beliefs of creditors may be summarized by a single number $x_{b}$, which may be thought of as "reputation" of the country. For example, if the country goes through a deep recession without defaulting, the cutoff $x_{b}$ will increase.

The value of a country deciding whether to default or not may be written as

$$
V\left(a, y, x, x_{b}\right)=\max \left\{V^{G}\left(a, y, x, x_{b}\right), V^{B}(y, x)\right\}
$$

where $a$ represents country's assets, the cutoff $x_{b}$ fully characterizes the creditors' beliefs, and $V^{B}$ and $V^{G}$ are the values in the default and non-default states. If the country defaults, its value function is

$$
V^{B}(y, x)=u((1-x) y)+\beta(1-\lambda) E_{y^{\prime} \mid y} V^{B}\left(y^{\prime}, x\right)+\beta \lambda E_{y^{\prime} \mid y} \int_{x_{\min }}^{x_{\max }} V\left(0, y^{\prime}, x^{\prime}, x_{\min }\right) \varphi\left(x^{\prime}\right) d x^{\prime}
$$

with time. 
with $\beta$ denoting the discount factor. The new cost of default $x^{\prime}$ is drawn at the time of redemption, and therefore the country's reputation $x_{b}$ is reset to its lowest possible value $x_{m i n}$.

There are many equilibria pooling with respect to the choice of assets in the non-default state, characterized by a "prescribed" level of assets next period $a^{\prime}$ that depends on the current observed state variables $a, y$, and $x_{b}$. As a baseline we consider one such equilibrium, in which the welfare of the pool of non-defaulted countries is maximized: ${ }^{5}$

$a^{\prime}\left(a, y, x_{b}\right)=\underset{a^{\prime}}{\arg \max } \int_{x_{b}^{\prime}\left(a, y, x_{b}\right)}^{x_{\max }}\left[u\left(y+a-q\left(a^{\prime}, a, y, x_{b}\right) a^{\prime}\right)+\beta E_{y^{\prime} \mid y} V\left(a^{\prime}, y^{\prime}, x, x_{b}^{\prime}\left(a, y, x_{b}\right)\right)\right] \varphi(x) d x$.

The welfare is maximized for a given price schedule $q($.$) of a bond that pays 1$ in the next period, and the law of motion for reputation $x_{b}^{\prime}($.$) , both of which will be defined later in this section. Note$ that $x_{b}$ represents the reputation from the previous period, while the current period reputation is described by $x_{b}^{\prime}$.

Then in the non-default state value function can be expressed as

$V^{G}\left(a, y, x, x_{b}\right)=u\left(y+a-q\left(a^{\prime}\left(a, y, x_{b}\right), a, y, x_{b}\right) a^{\prime}\left(a, y, x_{b}\right)\right)+\beta E_{y^{\prime} \mid y} V\left(a^{\prime}\left(a, y, x_{b}\right), y^{\prime}, x, x_{b}^{\prime}\left(a, y, x_{b}\right)\right)$

for given $q(),. a^{\prime}(),. x_{b}^{\prime}($.$) and subject to incentive compatibility (IC) constraint. Along the equilib-$ rium path the country always chooses the prescribed level of assets for the next period. However, it has the option to deviate and face out-of-equilibrium beliefs of the creditors. As with any pooling equilibrium, this particular equilibrium can be supported with many different out-of-equilibrium beliefs. ${ }^{6}$ As a baseline we consider the extreme case where any deviation makes the creditors believe that the country is of the worst possible type, $x_{m i n} .{ }^{7}$ Then the IC constraint can be expressed as

$$
V^{G}\left(a, y, x, x_{b}\right) \geq \max _{a^{\prime}}\left[u\left(y+a-\frac{1-E_{y^{\prime} \mid y} \tilde{D}\left(a^{\prime}, y^{\prime}, x_{\text {min }}\right)}{1+r} a^{\prime}\right)+\beta E_{y^{\prime} \mid y} \tilde{V}\left(a^{\prime}, y^{\prime}, x, x=x_{\text {min }}\right)\right],
$$

where $\tilde{D}($.$) is the default indicator function in the model with complete information and \tilde{V}\left(a^{\prime}, y^{\prime}, x, x=x_{\text {min }}\right)$

\footnotetext{
${ }^{5}$ As a robustness check, we consider other equilibria in a later section.

${ }^{6}$ More precisely, the same outcomes on the equilibrium path can be achieved with many different out-ofequilibrium beliefs.

${ }^{7}$ Again, we perform a robustness check with respect to other out-of-equlibrium beliefs in a later section.
} 
is the value function for a country with a cost of default $x$ that faces a bond price schedule determined by the beliefs that the country is of the worst possible type, $\left(1-E_{y^{\prime} \mid y} \tilde{D}\left(a^{\prime}, y^{\prime}, x_{\min }\right)\right) /(1+r)$. The condition (5) should hold for all states $\left(a, y, x, x_{b}\right)$ in which country does not default, i.e., $V^{G}\left(a, y, x, x_{b}\right) \geq V^{B}(y, x)$.

International creditors are assumed to be risk neutral and perfectly competitive. Therefore the bond price schedule is given by

$$
q\left(a^{\prime}, a, y, x_{b}\right)=\frac{\int_{x_{b}^{\prime}\left(a, y, x_{b}\right)}^{x_{\max }}\left[1-E_{y^{\prime} \mid y} D\left(a^{\prime}, y^{\prime}, x, x_{b}^{\prime}\left(a, y, x_{b}\right)\right)\right] \varphi(x) d x}{(1+r) \int_{x_{b}^{\prime}\left(a, y, x_{b}\right)}^{x_{\max }} \varphi(x) d x}
$$

where $D($.$) is the default indicator function$

$$
D\left(a, y, x, x_{b}\right)=1_{V^{G}\left(a, y, x, x_{b}\right)<V^{B}(y, x)} .
$$

Finally, as the default decision is monotone in $x$, for every observable state $\left(a, y, x_{b}\right)$ in which some countries default and some do not, i.e., $D\left(a, y, x_{\max }, x_{b}\right)=0$ and $D\left(a, y, x_{\min }, x_{b}\right)=1$, there must exist a level of the cost of default $\bar{x}$ such that the country is indifferent with respect to the default decision. We define the function $\bar{x}\left(a, y, x_{b}\right)$ implicitly using the corresponding indifference condition

$$
\bar{x}\left(a, y, x_{b}\right): \quad V^{G}\left(a, y, \bar{x}, x_{b}\right)=V^{B}(y, \bar{x})
$$

Then the law of motion for reputation can be expressed as

$$
x_{b}^{\prime}\left(a, y, x_{b}\right)=\max \left\{x_{b}, \bar{x}\left(a, y, x_{b}\right)\right\} .
$$

Note that in the non default state the reputation can only increase. Also, reputation is not updated every period. For example, if a country does not default during a period when no country does not want to default, this observation does not reveal any information about this country's cost of default.

The equilibrium we work with is defined to be a set of functions $\left\{V, V^{G}, V^{B}, q, a^{\prime}, \bar{x}, x_{b}^{\prime}, D\right\}$ satisfying the system of equations (1)-(9). We provide details about numerical solution to this system in the appendix. 


\section{Results}

\subsection{Model calibration}

To illustrate the properties of the model, we perform a simple calibration, with parameter values motivated by quarterly business cycle moments of Argentina. Table 1 summarizes our parameter choices, which are identical to those in Aguiar and Gopinath (2006), except for the newly introduced distribution of cost of default, a uniform distribution ${ }^{8}$ with support $\left[x_{\min }, x_{\max }\right]$. We calibrate length of the interval $\left[x_{\min }, x_{\max }\right]$ to match Argentina's rate of default exactly. ${ }^{9}$

\begin{tabular}{lcc}
\hline Coefficient of risk aversion & $\gamma$ & 2 \\
Probability of redemption & $\lambda$ & $10 \%$ \\
Persistence of income & $\rho_{z}$ & 0.9 \\
Standard deviation of income & $\sigma_{z}$ & $3.4 \%$ \\
Discount factor & $\beta$ & 0.8 \\
Risk-free interest rate & $r$ & $1 \%$ \\
Support of the distribution of $x$ & {$\left[x_{\min }, x_{\max }\right]$} & {$[0.5 \%, 8 \%]$} \\
\hline
\end{tabular}

Table 1: Calibration

\subsection{Numerical results}

We solve for the equilibrium numerically, with details of the computation provided in the appendix.

\subsubsection{Interest rate schedule}

Next, we illustrate the main feature of the resulting pooling equilibrium in Figure 1. Specifically, we plot the bond price $q\left(a^{\prime}, a, y, x_{b}\right)$ as a function of $a^{\prime}$ at the median income realization $y$ and for several possible values of $a$ and $x_{b}{ }^{10,11}$

First, note that when the current reputation $x_{b}^{\prime}$ is close to the maximum value of the cost of default $x_{\max }$, the model is essentially the same as in the full information case. This corresponds to

\footnotetext{
${ }^{8}$ We discuss the consequences of different shapes of the distribution of cost of default in section 3.2.2.

${ }^{9} \mathrm{By}$ choosing particular values of the interval $\left[x_{\min }, x_{\max }\right]$ we don't literally mean that the most responsible country will suffer output loss of $x_{\max }$ in the case of default. Since we don't take a stand on what drives unobserved heterogeneity between countries and just model it in reduced form as cost of default, the length of the interval $\left[x_{\min }, x_{\max }\right]$ should be interpreted as amount of underlying unobserved heterogeneity between countries whatever nature it could have.

${ }^{10}$ Recall from Equation 6 that the current debt level $a$ affects bond prices only through the belief updating process $x_{b}^{\prime}\left(a, y, x_{b}\right)$. Thus all possible values of debt $a$ and past reputation $x_{b}$ in the Figure 1 in fact just represent different possible values of the current reputation $x_{b}^{\prime}$.

${ }^{11}$ For illustration purposes here we present the interest rate schedule of the model with $x_{\max }=50 \%$ and $\sigma_{z}=6.8 \%$.
} 


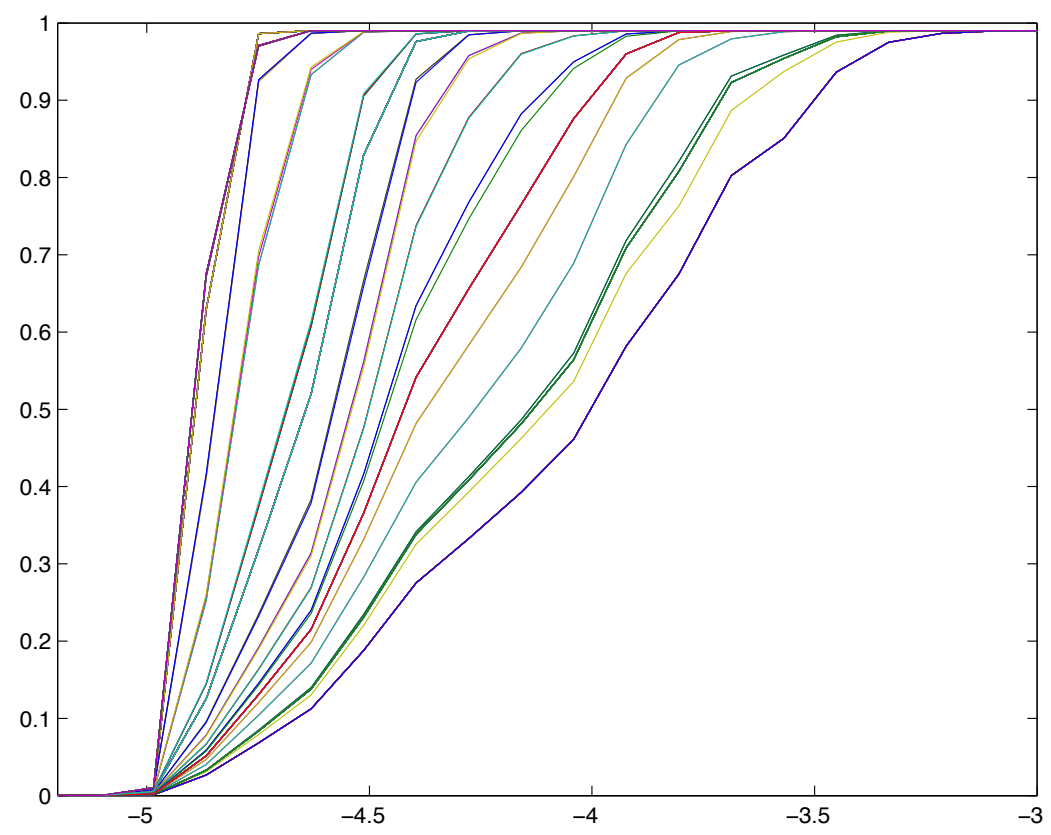

Figure 1: Interest rate schedule

the left-most bond price curve in Figure 1. It is extremely steep and therefore strongly discourages the countries from borrowing enough to enter the region with a non-trivial probability of default, as in the previous literature.

Second, when the current reputation $x_{b}^{\prime}$ is close to the minimum possible value $x_{m i n}$, the model features a maximum "amount of pooling" in the sense that the creditors have the least amount of information. This case corresponds to the right-most bond price curve in Figure 1. It is much more flat than the schedule for the full information case. The reason is that here the creditors are confused about the true cost of default. Intuitively, we can think of this flat curve as an average of steep perfect-information bond price curves corresponding to the different possible values of $x$, in the sense of Equation 6. As we go from the right to the left along this flat curve, the bond price starts to significantly deviate from the risk-free bond price. This level of assets corresponds to the "default point" of the country with the lowest $x$. Further to the left, the bond price drops to zero. This corresponds to the "default point" of the country with the highest $x$.

Then, all the intermediate curves are in between of the curves for $x_{b}^{\prime}=x_{\min }$ and for $x_{b}^{\prime}=x_{\max }$. With higher reputation, the country can borrow with a negligible risk premium for a wider range 
of assets and faces a steeper interest rate schedule below this range.

Note that a flat interest rate schedule encourages countries to borrow at non-trivial interest rates. Even though responsible countries have no incentives to default in such regions, irresponsible ones will have a positive probability of default in the next period. This mechanism explains the high frequency of default of such irresponsible countries in the simulations.

\subsubsection{The role of the shape of default-cost distribution}

The shape of the distribution of cost of default influences the default rate for individual countries. If the distribution is more skewed towards small $x$, the rate of default increases, and vice versa. Let's consider an extreme example. Suppose that the creditors assign unit probability to $x_{\max }$. In this case countries with $x=x_{\max }$ will behave as in the perfect information model of Aguiar and Gopinath (2006). In particular, such countries would face very high interest rates near their default point, which would deter them from approaching it. However countries with small $x$ will not be deterred from their default point, corresponding to a significantly lower amount of debt. As a result, such countries will default with a high probability.

\subsubsection{Simulations}

As an illustration, we run a simulation for a country with the cost of default equal to $40 \%$ in the model with the maximum cost of default of $50 \%$ (and $\sigma_{z}=6.8 \%$ ). We chose these larger values in order to make the patterns more clearly visible, but the parameter values from Table 1 would lead to the same qualitative behavior. Here we do not intend to match business cycle moments for Argentina, but instead our goal is to illustrate the "graduation from default" phenomenon as well as other empirical regularities. One example of such simulation for the first 400 quarters is depicted in Figure 2. Three features stand out.

First, graduation from default may be clearly seen from the simulation path. The simulation started with a very responsible country that had the minimum possible reputation. The highest interest rate spread the country had to pay during first 10-15 years (40-60 quarters) was about $5 \%$ (quarterly interest rate spread of $1.23 \%$ ). As the country went through recessions without defaulting, it earned higher reputation and enjoyed lower interest rates as a result.

Second, the spikes in interest rates decrease over time as the country gains higher reputation. 
Debt, \% of annual GDP
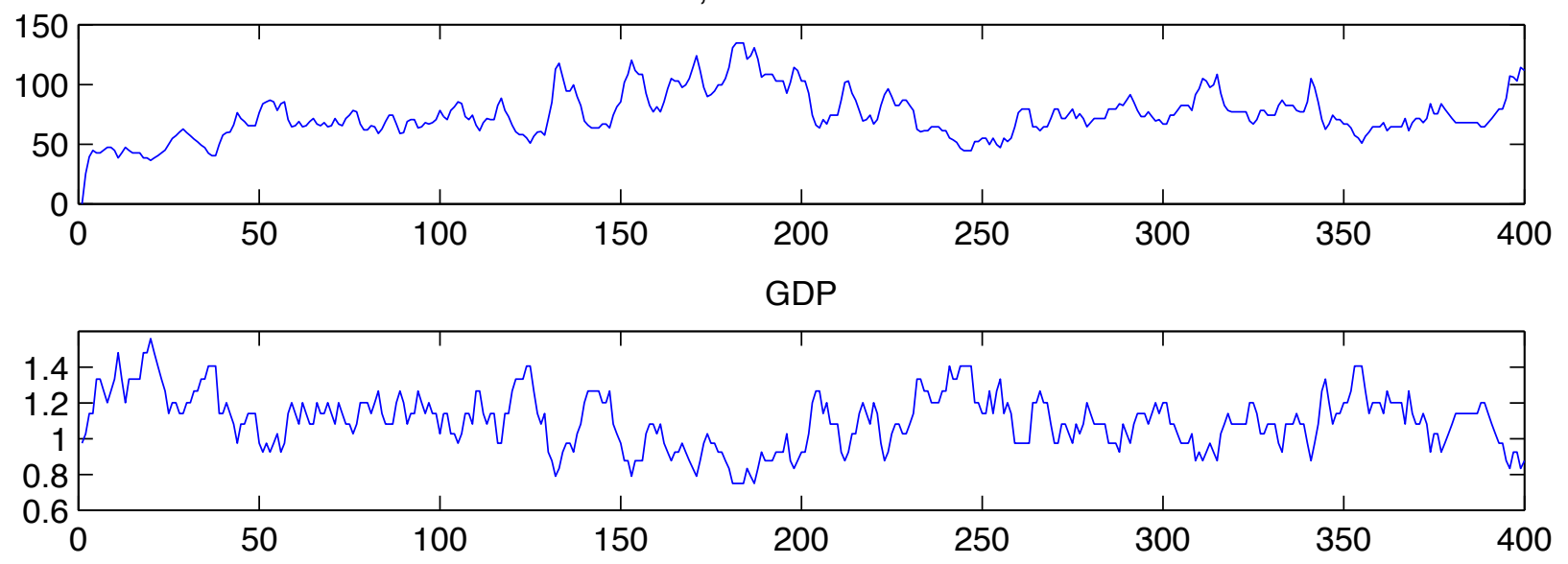

Interest Rate Spread, \%
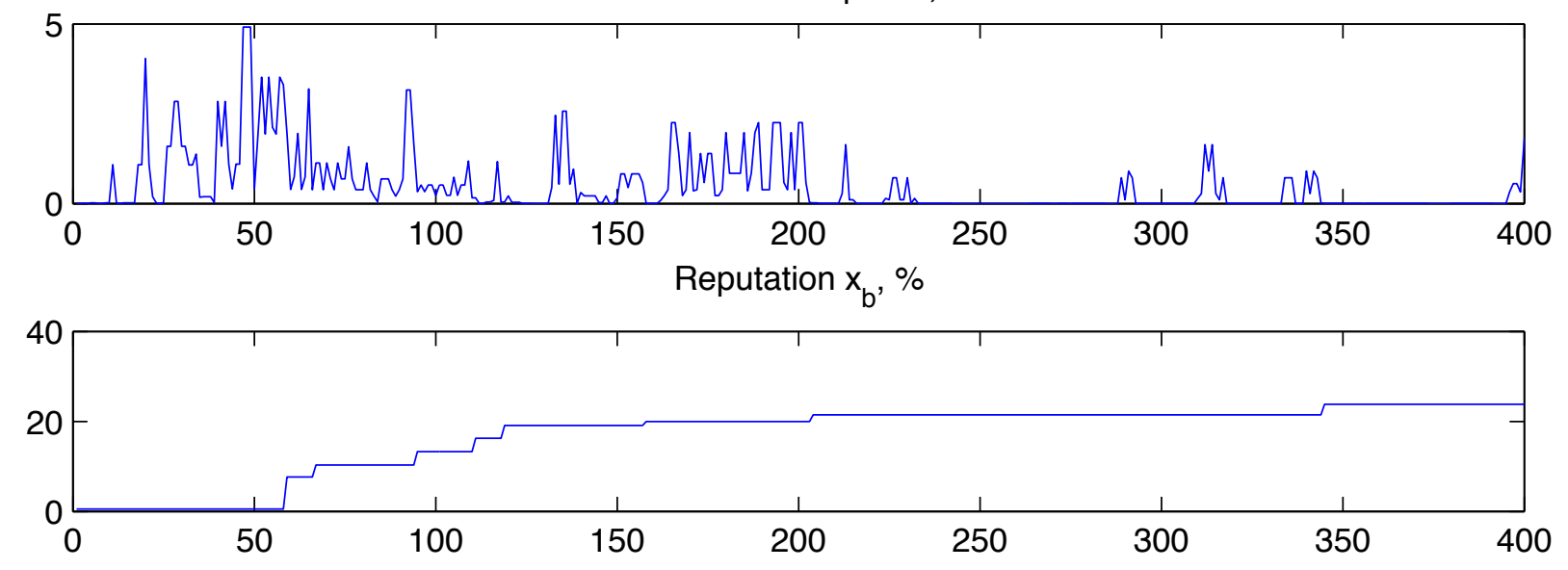

Figure 2: An example of a simulation path for country with $40 \%$ cost of default 
Moreover, this process is accompanied by an increase of the debt ceiling. This is another benefit of higher reputation in addition to lower interest rates.

Finally, earning a high reputation is a gradual and also "concave" process: the country relatively quickly gained a reputation of, say, 20\%, but after that every small gain in reputation took a lot of time. The reason is that even a mild recession can help to distinguish a very irresponsible country (say, with a $1 \%$ cost of default) from a quite responsible one (say, with a $10 \%$ cost of default). But it takes an unusually severe recession to distinguish a $10 \%$ country from a $20 \%$ one. Highly responsible countries typically have to wait for several decades (if not centuries) to signal their true type by not defaulting during severe recessions. ${ }^{12}$

Next, we turn to an analysis of business cycle moments.

\subsubsection{Business cycle statistics}

To obtain moments generated by the model, we run simulations for a country with the cost of default equal to $2 \%{ }^{13}$ For the purposes of computing statistics we let the country draw the same value of $x$ after each default, even though both the creditors and the country itself expect it to be drawn from the unconditional distribution $\varphi(x)$. We interpret this simulation not as a likely path of economic outcomes, but rather as an average path between two default episodes for a country with a $2 \%$ cost of default. The results, presented in Table 2 , show that the model performs well in this respect.

\footnotetext{
${ }^{12}$ Compare it with Qian, Reinhart, and Rogoff (2010) who find that "2 decades without a relapse (falling into crisis) is an important marker. [...] However, crisis recidivism distributions have very fat tails, so that it takes at least 50 and perhaps 100 years to meaningfully speak of "graduation"."

${ }^{13}$ We take this value from calibration in Aguiar and Gopinath (2006).
} 
Table 2: Business Cycles Moments

\begin{tabular}{lccc}
\hline Moment & Data & $\begin{array}{c}\text { Model with } \\
\text { imperfect } \\
\text { information }\end{array}$ & $\begin{array}{c}\text { Aguiar and } \\
\text { Gopinath } \\
(2006) \text { - Model }\end{array}$ \\
\hline$\sigma(y)$ & 4.08 & 5.82 & I \\
$\sigma(c)$ & 4.85 & 7.37 & 4.32 \\
$\sigma(T B / y)$ & 1.36 & 1.50 & 0.17 \\
$\sigma(R)$ & 3.17 & 0.88 & 0.04 \\
$\operatorname{corr}(c, y)$ & 0.96 & 0.86 & 0.99 \\
$\operatorname{corr}(T B / y, y)$ & -0.89 & -0.08 & -0.33 \\
$\operatorname{corr}(R, y)$ & -0.59 & 0.02 & 0.51 \\
$\operatorname{corr}(R, T B / y)$ & 0.68 & 0.29 & -0.21 \\
$\operatorname{Rate}$ of default (per 10,000 quarters) & 75 & 74 & 2 \\
Mean debt output ratio (\%) & & 75 & 27 \\
Maximum $R$ (basis points) & & 396 & 23 \\
\hline
\end{tabular}

The column labelled "Data" as well as the last column are taken from Aguiar and Gopinath (2006). Following their procedure, we took logarithms of both income and consumption; their standard deviations are denoted $\sigma(y)$ and $\sigma(c)$, respectively, and similarly for correlations. The trade balance $T B$ is calculated as income minus consumption. $R$ denotes the annualized interest rates spread. All series were Hodrick-Prescott filtered with a smoothing parameter of 1600 .

\section{Conclusions}

We presented a calibrated model of sovereign debt with information asymmetry that is well suited for empirical analysis because its structure is close to standard perfect-information models and because it allows for gradual gains in reputation. In ongoing work we compare the qualitative and quantitative features of the model to the data on sovereign borrowing for numerous countries, developed and developing. Performing such analysis is meaningful because in our framework lowrisk and high-risk sovereign borrowers are represented simply by different parts of the same state space. Numerous generalizations of our model are possible, and we plan to explore them in future work. 


\section{References}

[1] Aguiar, M. and Gopinath, G. (2006). Defaultable debt, interest rates and the current account. Journal of international Economics, 69(1), 64-83.

[2] Alfaro, L., \& Kanczuk, F. (2005). Sovereign debt as a contingent claim: a quantitative approach. Journal of International Economics, 65(2), 297-314.

[3] Arellano (2008). Default Risk and Income Fluctuations in Emerging Economies. American Economic Review, 98, 690-712

[4] Atkeson, A. (1991). International lending with moral hazard and risk of repudiation. Econometrica: Journal of the Econometric Society, 1069-1089.

[5] Barrett (2015), Sovereign Default, Spreads, and Reputation. Working paper.

[6] Catão, L. A., Fostel, A., and Kapur, S. (2009). Persistent gaps and default traps. Journal of Development Economics, 89(2), 271-284.

[7] Catão, L., Fostel, A., and Ranciere, R. (2011). Sudden Stops and Sovereign Defaults. Paris School of Economics working paper.

[8] Chatterjee, Corbae and Ríos-Rull (2011). A Theory of Credit Scoring and Competitive Pricing of Default Risk. Working paper

[9] Cole, H. L., Dow, J., and English, W. B. (1995). Default, settlement, and signalling: Lending resumption in a reputational model of sovereign debt. International Economic Review, 365-385.

[10] Cole, Neuhann, and Ordonez (2015). Debt Crises: For Whom the Bell Tolls. Working paper.

[11] D'Erasmo, P. N. (2011). Government Reputation and Debt Repayment in Emerging Economies. Working paper.

[12] Dovis, A. (2014). Efficient Sovereign Default. Working paper.

[13] Kletzer, K. M. (1984). Asymmetries of information and LDC borrowing with sovereign risk. The Economic Journal, 287-307. 
[14] Onder (2014). Sovereign Default and Cheap Talk. Working paper.

[15] Phan, T. (2014). Sovereign Debt Cycles. Working paper.

[16] Phelan (2006). Public trust and government betrayal. Journal of Economic Theory 130 (2006) $27-43$.

[17] Reinhart, C. M. and Rogoff, K. S. (2009). This Time Is Different: Eight Centuries of Financial Folly. Princeton University Press.

[18] Sandleris, G. (2008). Sovereign defaults: Information, investment and credit. Journal of International Economics, 76(2), 267-275.

[19] Sandleris, G. (2014). Sovereign defaults, credit to the private sector, and domestic credit market institutions. Journal of Money, Credit and Banking, 46(2-3), 321-345.

[20] Qian, R., Reinhart, C. M., and Rogoff, K. (2010). On Graduation from Default, Inflation, and Banking Crises: Elusive or Illusion? NBER Macroeconomics Annual, 25(1), 1-36. 